\title{
Do Public Awareness and Behaviors in Rural Domestic Waste Classification Help Reduce COVID-19? a Case Study in China
}

\author{
Bing Zheng", Sanyu Wan ${ }^{1}$, Jing Wen ${ }^{1}$, Lu Ye ${ }^{1 *}$, Kaibo Lv \\ ${ }^{1}$ Research Center for Ecological Civilization, College of Economics and Management, \\ Zhejiang Sci-Tech University, Hangzhou, 310018, China \\ ${ }^{2}$ School of Finance, Zhejiang Gongshang University, Hangzhou, 310018, China
}

Received: 7 October 2020

Accepted: 29 November 2020

\begin{abstract}
Rural domestic waste classification (RDWC) is one of the main strategies for waste management, which plays a significant role in the circular economy and sustainable management. As one of the first pilot cities of waste classification in China, Hangzhou took the lead in promoting the classification and recycling of rural domestic waste. Based on the probability sampling procedure, this study focuses on the influencing factors of residents' awareness and behaviors toward RDWC in Hangzhou rural areas. The results of the questionnaire survey show that the perception of the importance of RDWC is weak in rural areas of China. Moreover, regression analyses show that the public's RDWC awareness is positively influenced by the cleanliness of waste rooms, age, and educational level. And their RDWC behaviors are negatively influenced by human supervision but positively influenced by the attitude to waste classification, satisfaction with the situation of RDWC and environment. Besides, exploring the relationship between the number of COVID-19 cases and the waste classification performance shows cities with better waste classification performance have fewer confirmed cases. These results imply that the proper waste classification methods and supporting infrastructure facilities could be fitted to other rural areas.
\end{abstract}

Keywords: rural domestic waste classification, probability sampling procedure, public awareness, public behavior, COVID-19

\section{Introduction}

There is a growing worldwide concern over waste management. As the world's most populous country

*e-mail: zjwzajyl@hotmail.com and the fourth largest in area, China has experienced a high rate of economic growth and a change of lifestyle in rural areas. However, the Chinese government did not pay enough attention to it, which leads to the rising tide of domestic waste in rural areas in China [1]. At present, two-thirds of China's big and medium cities are engulfed in waste, with more than 
500 million square meters of land nationwide encroached by domestic waste [2]. Thus, many cities are facing a dilemma that cities are surrounded by garbage in suburban or rural areas in China, which has a great impact on the local environment [3, 4]. To control the growing domestic waste, some cities in well-developed regions have launched waste classification programs since the 1990s. Subsequently, in 2000, eight cities, Beijing, Shanghai, Guangzhou, Shenzhen, Hangzhou, Nanjing, Xiamen, and Guilin, were selected as pilot cities to explore the waste classification system in the urban areas [5]. Since 2014, the "classified reduction, source traceability, fixed-point delivery, and centralized treatment" rural domestic waste classification (RDWC) model has been actively promoted in Zhejiang Province. Therefore, it is urgent to explore realistic and effective methods to implement a waste classification policy.

Many previous studies have shown that public awareness and attitude are the basis of successful waste classification [6, 7]. Generally, the samples used in different studies have gotten contradictory conclusions. Based on stratified sampling to select 3047 households in Delhi, India, the public knowledge about waste management had a significant correlation with the willingness to take part in RDWC [8]. Moreover, the female, the older, the lower socioeconomic, and the highest socioeconomic had greater knowledge of waste management. Pakpour et al. found that attitudes, subjective norms, perceived behavioral control, moral obligations, self-identify, intention, action planning, and past behavior significantly predicted behaviors of RDWC in Iran [9]. In China, the attitude towards RDWC, subjective norms, perceived behavioral control, and experience can significantly influence public awareness [4]. Based on quota, systematic, and convenience sampling to select 200 households in Tuobodom, Ghana, Kwetey et al. found that socioeconomic characteristics such as age, education, income, and employment had no significant effects on willingness to pay for waste management [10]. Besides, the conclusions of different studies can be inconsistent even in the same country. $\mathrm{Ma}$ et al. applied multistage sampling to select 312 households in Guilin, China. The results show that monthly income had a positive correlation with public environmental attitudes but age, gender, and education had no significant correlation with public environmental attitudes [11]. Selecting 811 households in 59 villages from six provinces in West China, Han et al. found that education, demonstration projects and public awareness of waste treatment necessity had significantly positive effects on public willingness to participate in domestic waste management in rural areas of China. The older had a weaker willingness to participate in RDWC compared with the younger [12].

The outbreak of the novel coronavirus (COVID-19) was a global epidemic event that started in late 2019 and was declared a pandemic by the World Health Organization in March 2020 [13]. Early studies mainly focused on the risk factors of the epidemic from a personal perspective, such as age and history of smoking [14, 15]. Now, focused on environmental factors, many studies have shown that the outbreak of COVID-19 was influenced by air pollution [16], nitrogen dioxide level [17], and waste management [18]. Mol and Caldas found that the spread of the novel coronavirus may be increased by inadequate waste management, highlighting poor handling conditions associated with inappropriate use of personal protective equipment in developing countries [18]. Since RDWC is one of the main strategies for waste management, we assessed the association between domestic waste classification and the spread of COVID-19, and provide specific suggestions to public awareness and behaviors in RDWC to help reduce COVID-19.

To better understand public awareness and behaviors in RDWC and explore the relationship with novel coronavirus, we conduct a questionnaire survey in rural areas of Hangzhou, the capital city of Zhejiang Province, China, which has been practicing RDWC since 2014. It is documented that the knowledge of rules of the separate collection does not necessarily mean that residents translate these into action [19]. To better identify the significant influencing factors of RDWC awareness and behaviors, this paper applies questionnaires and probability sampling methods, which ensures the sample can represent the population perfectly and regression analyses are applied for credibility. With the focus on RDWC awareness and behaviors, the regression results show that the influencing factor of public awareness and behaviors are inconsistent. The results also reveal that the crucial influencing factors of RDWC awareness are different from the influencing factors of public behaviors. The contributions of the paper are threefold.

First, the results of this study provide an empirical reference for local governments to standardize the classification measures, strengthen the infrastructure construction, and promote publicity and education, the practical experience of which is worth strongly popularizing. Hangzhou is one of the first pilot cities of waste classification in China. In 2015, the Hangzhou government published the 'Three-year Action Plan for Classification and Reduction of Rural Domestic Waste'. After four years of development, Hangzhou formed a series of systems for the classified deposit, collection, transportation, and disposal of garbage in rural areas [20]. Yu and Shen found that when formulating environmental regulation policies, each region should match the local economic development level and industrial structure [21]. The same is true for the RDWC policy. When formulating RDWC policies, each region should match the local cultural environment and ecological environment. This study provides specific evidence to the government for taking more effective policies and promoting the experience of RDWC to more rural areas in China, even the world.

Second, probability sampling is applied to avoid selection bias and make the results scientifically 
credible. Besides, to better understand and identify the significant influencing factors of RDWC awareness and behaviors, regression analyses are applied based on a valid sample. Cronbach's alpha coefficient of the survey is 0.713 , greater than 0.6 [22]. Therefore, it can be considered that the information obtained through the questionnaire has high reliability. The KMO value of the survey was 0.745 , greater than 0.7 , and the significance value was 0.00 , less than 0.05 , indicating that the survey results are in agreement with the facts and can be used for the data analysis.

Third, exploring the relationship between the number of COVID-19 cases and the waste classification performance reveals the need for improvement of waste classification. We compared the confirmed number of COVID-19 cases with domestic waste classification performance within 13 provinces, which have more than one city on the rank list. Nine-thirtieth cities, which have the higher, had controlled the COVID-19 better. During the novel coronavirus epidemic, everyone was living in their homes and working from home, leading to an increase in domestic waste. At the same time, a large number of used masks and disposable gloves have also become new domestic waste. Public awareness and behavior to RDWC can effectively prevent the spread of the virus. This study provides evidence to improve the flexibility of waste classification policy.

The rest of this paper is organized as follows: Section 2 provides the probability sampling method, which is used to collect data. Section 3 describes the data statistically. Section 4 presents regression analyses about the RDWC awareness and behavior and exploration of the relationship between the number of COVID-19 cases and the waste classification performance. Section 5 concludes and provides some specific suggestions.

\section{Material and Methods}

\section{Sample Size and Sampling Procedure}

All households owned a residential house in the rural areas of Hangzhou were eligible to participate in the study. To investigate the rural residents in the study area, the sampling procedure follows Babbie's multistage sampling approach [23]. $N_{1}$ is the number of districts in Hangzhou; $N_{2}, N_{3}, N_{4}$ are the average number of towns per district, villages per town, and farmers per village. The lowercase equivalents $\left(n_{1}, n_{2}, n_{3}\right.$ and $\left.n_{4}\right)$ are the corresponding numbers in the samples. The average cost of investigating each district, town, village, and farmer is denoted as $C_{1}, C_{2}, C_{3}$ and $C_{4}$.

According to the data from the Hangzhou Statistics Bureau of 2017, Hangzhou covers 13 districts and 190 towns. Only 8 districts consist of rural areas, so, $N_{1}=8$. Then, based on the information of each district from the National Bureau of Statistics, we calculated that $N_{2}=14, N_{3}=12$ and $N_{4}=317$.
The optimal sample size was required. This can either be to maximize the precision of the estimate subject to a specified cost or to achieve a specified precision expressed as the variance. As the variance of the population was not available, it was possible to investigate with the former option. Set one half of the length of the confidence interval of the population mean as $5 \mathrm{CNY}$ (tolerable error $\theta=5$ ). Set the confidence level $\alpha$ as 0.05 . When the limited value of $\mathrm{V}=\left(\theta / \mathrm{z}_{\alpha / 2}\right)^{2}$, the survey was the most cost-effective. $\mathrm{V}$ is denoted the variance of the population mean. By taking account of the multistage sampling design and the cost of each stage, optimum sample sizes can be estimated by the following equations:

$$
\begin{aligned}
& n_{2}=\sqrt{\frac{\sigma_{2}{ }^{2}-\sigma_{3}{ }^{2} / N_{3}}{\sigma_{1}{ }^{2}-\sigma_{2}{ }^{2} / N_{2}} \cdot \frac{C_{1}}{C_{2}}} \\
& n_{3}=\sqrt{\frac{\sigma_{3}{ }^{2}-\sigma_{4}{ }^{2} / N_{4}}{\sigma_{2}{ }^{2}-\sigma_{3}{ }^{2} / N_{3}} \cdot \frac{C_{2}}{C_{3}}} \\
& n_{4}=\sqrt{\frac{\sigma_{4}{ }^{2}}{\sigma_{3}{ }^{2}-\sigma_{4}{ }^{2} / N_{4}} \cdot \frac{C_{3}}{C_{4}}} \\
& n_{1}=\frac{\left(\sigma_{1}{ }^{2}-\sigma_{2}{ }^{2} / N_{2}\right)+\left(\sigma_{2}{ }^{2}-\sigma_{3}{ }^{2} / N_{3}\right) / n_{2}+\left(\sigma_{3}{ }^{2}-\sigma_{4}{ }^{2} / N_{4}\right) / n_{3}+\sigma_{4}{ }^{2} /\left(n_{2} n_{3} n_{4}\right)}{V+\sigma_{1}{ }^{2} / N_{1}}
\end{aligned}
$$

...where $\sigma_{1}^{2}, \sigma_{2}^{2}, \sigma_{3}^{2}$ and $\sigma_{4}^{2}$ are denoted as the variance of the first, the second, the third, and the fourth stage. Considering the variance of the population was not available, we used our pre-survey data to estimate the variance of each stage. The results were $C_{1}=500 \mathrm{CNY}$, $C_{2}=100 \mathrm{CNY}, C_{3}=10 \mathrm{CNY}$ and $C_{4}=1 \mathrm{CNY}$. We also calculated that $S_{1}^{2}=12$, by the average cost of presurveying each stage.

Applying the data to the four equations, we calculated the optimal sample size for each stage, $n_{1}=3, n_{2}=3, n_{3}=4, n_{4}=9$. First, three districts were selected from eight districts in Hangzhou by Probability Proportional to Size sampling (PPS) technique using the number of farmers in each district. Then, three towns were selected from the three sample districts by the Simple Random Sampling (SRS) technique using the zoning code. Four villages were also selected from the three sample towns by the SRS technique using the urban and countryside classification code. Finally, nine participant families were selected by the SRS technique using the house number we defined by GIS-assisted mapping. For the cases where no one answered, we tried to find residents in the farmland or made a second visit later.

\section{Data Processing}

In this study, a questionnaire was designed to obtain the basic need for the analysis. First, the designed questionnaire contained a series of questions about the situation and awareness of RDWC. Then, the questionnaire followed a series of questions about the local environment and the facilities and rules of RDWC. Finally, the questionnaire surveyed the respondents' 
gender, age, educational level, occupation, and monthly income. In total, 400 questionnaires were distributed to respondents. The cover letter attached to the questionnaires assured participants of their anonymity. Finally, 324 valid questionnaires were used in this research, resulting in an $81 \%$ usable response rate. The collected questionnaires were numbered and classified to use the number to retrieve the original questionnaire for reconciliation correction.

\section{Reliability and Validity Analysis}

Two tests were carried out by R. The first test was Bartlett's Test of Sphericity (BTS), which was used to evaluate the significance of the data matrix and the second test was Kaiser-Meyer-Olkin (KMO) which measured the correlation between factors [24].

According to Jomeen and Martin, Cronbach's alpha coefficient of 0.6 was considered as the minimum acceptable criterion for the internal reliability of the instrument [22]. Cronbach's alpha coefficient of the survey is 0.713 . Therefore, it can be considered that the information obtained through the design of the questionnaire has high reliability and can be used to evaluate RDWC in Hangzhou. The KMO value of the survey was 0.745 , greater than 0.7 , and the significance value was 0.00 , less than 0.05 , indicating that the survey results were in agreement with the facts and can be used for the following data analysis.

\section{Results and Discussion}

\section{Demographics of Respondents}

It is universally accepted that demographic structure and education level will affect the RDWC [8, 25-27]. Table 1 shows the gender, age, education, and occupation distribution in the investigated districts. For analysis, all respondents are categorized into six categories in terms of age: $<19,19$ to 29,30 to 39,40 to 49,50 to 59 , and $>=60$ years old. The distributions of respondents in all categories are $3.09 \%, 56.17 \%$, $10.19 \%, \quad 19.75 \%, \quad 6.79 \%$, and $4.01 \%$, respectively. The result showed that the main RDWC role of each household was mainly concentrated in the young and middle-aged people. Therefore, the young and middle-aged were the major contributors to RDWC. In contrast, their education levels were relatively low compared to residents living in urban areas. Thus, more than half of the respondents' monthly salary was below 2000CNY. Among the respondents, the scope of occupational distribution was relatively wide. Among them, students accounted for $42.59 \%$, housewives accounted for $12.65 \%$, workers (including migrant workers) accounted for $10.8 \%$, retirement or laid-off accounted for $6.17 \%$, self-employed accounted for $6.17 \%$, and public officials (including civil servants and public institutions) accounted for $6.17 \%$. The above
Table 1. Descriptive statistics of the demographics of the 324 respondents.

\begin{tabular}{|c|c|c|}
\hline Group & Variable & $\begin{array}{l}\text { Percentage } \\
\quad(\%)\end{array}$ \\
\hline \multirow{2}{*}{ Gender } & Male & 34.57 \\
\hline & Female & 65.43 \\
\hline \multirow{6}{*}{ Age } & $<19$ & 3.09 \\
\hline & $19-29$ & 56.17 \\
\hline & $30-39$ & 10.19 \\
\hline & $40-49$ & 19.75 \\
\hline & $50-59$ & 6.79 \\
\hline & $>=60$ & 4.01 \\
\hline \multirow{5}{*}{ Education } & Elementary school & 6.79 \\
\hline & Junior high school & 20.68 \\
\hline & Senior high school & 11.73 \\
\hline & College/diploma program & 60.49 \\
\hline & $\begin{array}{l}\text { University-undergraduate pro- } \\
\text { gram }\end{array}$ & 0.31 \\
\hline \multirow{10}{*}{ Occupation } & Officials & 6.17 \\
\hline & Self-employed & 6.17 \\
\hline & Business manager & 4.32 \\
\hline & Professional & 2.78 \\
\hline & Farmer & 3.40 \\
\hline & Retiree & 6.17 \\
\hline & Worker & 10.80 \\
\hline & Student & 42.59 \\
\hline & Housewife & 12.65 \\
\hline & Other & 4.94 \\
\hline \multirow{6}{*}{$\begin{array}{l}\text { Monthly } \\
\text { income }\end{array}$} & 0-1999 CNY & 54.63 \\
\hline & 2000-3999 CNY & 25.62 \\
\hline & 4000-7999 CNY & 11.73 \\
\hline & 8000-11999 CNY & 2.47 \\
\hline & 12000-19999 CNY & 0.93 \\
\hline & $>20000 \mathrm{CNY}$ & 4.63 \\
\hline
\end{tabular}

analysis of distribution of age and education level, occupations at all levels of society showed that the sample was representative.

\section{Descriptive Statistics and Correlation Analysis}

Table 2 presents the constructs, means, and standard deviations for all variables in this study. The mean of public awareness is 3.67 between neutral and agreement. To investigate the level of public 
Table 2. Descriptive statistics of all variables.

\begin{tabular}{|c|c|c|c|c|}
\hline \multicolumn{2}{|c|}{ Variables } & Constructs & Mean & Standard Deviation \\
\hline \multirow{2}{*}{$\begin{array}{c}\text { Dependent } \\
\text { variable }\end{array}$} & Awareness & Have you ever paid attention to RDWC? & 3.67 & 0.71 \\
\cline { 2 - 5 } & Behavior & Waste classification accuracy score. & 25.51 & 12.06 \\
\hline \multirow{2}{*}{$\begin{array}{c}\text { Subject } \\
\text { perception }\end{array}$} & Attitude & What's your opinion on implementing waste management? & 2.79 & 0.59 \\
\cline { 2 - 5 } & RDW satisfaction & Are you satisfied with the situation of RDWC in your village? & 3.07 & 0.90 \\
\hline \multirow{2}{*}{$\begin{array}{c}\text { Object } \\
\text { factors }\end{array}$} & Waste room & What is the cleanliness of waste rooms? & 2.82 & 0.70 \\
\cline { 2 - 5 } & Environment & What do you think of the environment in your village? & 2.81 & 0.58 \\
\cline { 2 - 5 } & Supervision & Are you subject to human supervision when handling & 0.27 & 0.44 \\
\hline
\end{tabular}

knowledge of RDWC, two questions were set up in the questionnaire to distinguish hazardous waste and recyclable waste. The data showed that the positive response rates for the two questions are $5.25 \%$ and $18.21 \%$, respectively. We assigned points to the options: 10 points for correct answers and -5 points for wrong answers. Then we added the two question scores and standardize the total scores to get the Behavior variable. But the mean of behavior is relatively low compared to the awareness, indicating that public RDWC behaviors are not consistent with their RDWC awareness.

Subject perception reflected the perception of respondents at a village level. Concerning implementing RDWC, respondents didn't hold a supportive attitude toward it, which had mean values 2.79 below the midpoint. However, for the satisfaction of RDWC, respondents held a fair attitude toward it, which had mean values around 3.0.

Objective factors reflected the situation of RDWC in the respondents' village. According to the survey, only $2.69 \%$ of respondents thought the environment of their living areas was poor, while $71.38 \%$ of them thought it needed improvement. Respondents felt satisfied with the environment and waste room, both of which had mean values around 2.8. For the supervision of RDWC, most of the villagers didn't have human supervision, which had a mean value of only 0.27 .
As is shown in Table 3, the result of correlation analysis indicated that awareness of environmental issues is positively associated with the cleanliness of waste rooms $(r=0.16 ; \mathrm{p}<0.01)$ and human supervision when handling domestic waste $(r=0.13 ; p<0.05)$. Waste classification behavior is positively associated with attitude to implementing waste management $(\mathrm{r}=0.25$; $\mathrm{p}<0.01)$, RDWC satisfaction $(\mathrm{r}=0.17 ; \mathrm{p}<0.01)$ and the environment in respondents' village $(r=0.21 ; p<0.01)$.

\section{Public Awareness and Behavior of RDWC}

To investigate the impact factors of public awareness and behavior of RDWC, this study adopted hierarchical regression analysis. The demographic variables, which were gender, age, education, and income, in the regression model were controlled for rural residents' awareness and behavior. Each regression analysis performed the same process, differing only in the dependent variable. So the model is set as follows:

Dependent variable $e_{\mathrm{i}}$

$=$ constant value $+b_{1}$ Gender $_{\mathrm{i}}+b_{2}$ Age $_{\mathrm{i}}+b_{3}$ Education $_{\mathrm{i}}$

$+b_{4}$ Monthly income $_{\mathrm{i}}+b_{5}$ Attitude $_{\mathrm{i}}+b_{6}$ RDWC Satisfaction $_{\mathrm{i}}$

$+b_{7}$ Waste room $_{\mathrm{i}}+b_{8}$ Environment $_{\mathrm{i}}+b_{9}$ Supervision $_{\mathrm{i}}+\varepsilon_{\mathrm{i}}$

Table 3. Correlations among the related variables.

\begin{tabular}{|c|c|c|c|c|c|c|c|}
\hline & 1 & 2 & 3 & 4 & 5 & 6 & 7 \\
\hline Awareness & 1 & & & & & & \\
\hline Behavior & 0.05 & 1 & & & & & \\
\hline Attitude & 0.08 & $0.25^{* * *}$ & 1 & & & & \\
\hline RDWC Satisfaction & 0.08 & $0.17^{* * *}$ & -0.02 & 1 & & & \\
\hline Waste room & $0.16^{* * *}$ & 0.07 & -0.01 & $0.22^{* * *}$ & 1 & & 1 \\
\hline Environment & $-0.10^{*}$ & $0.21^{* * *}$ & 0.00 & $0.17^{* * *}$ & 0.03 & 0.08 & 1 \\
\hline Supervision & $0.13^{* *}$ & -0.02 & 0.00 & $0.32^{* * *}$ & $0.15^{* * *}$ & 0.00 \\
\hline
\end{tabular}

Note: *significant at 0.1 level, $* *$ significant at 0.05 level, $* * *$ significant at 0.01 level. 
Table 4. Results of hierarchical regression analysis of awareness and behavior (OLS robust regressions).

\begin{tabular}{|c|c|c|c|c|c|c|}
\hline & \multicolumn{3}{|c|}{ Awareness } & \multicolumn{3}{c|}{ Behavior } \\
\hline & Model 1 & Model 2 & Model 3 & Model 1 & Model 2 & Model 3 \\
\hline Gender & 0.04 & 0.00 & 0.10 & 0.17 & 0.05 & 0.05 \\
\hline Age & $0.11^{* *}$ & $0.10^{* *}$ & $0.14^{* * *}$ & 0.01 & 0.01 & 0.03 \\
\hline Education & 0.08 & 0.08 & $0.10^{*}$ & -0.01 & 0.01 & 0.03 \\
\hline Monthly income & -0.01 & -0.01 & -0.03 & -0.04 & -0.03 & -0.02 \\
\hline Attitude & & 0.07 & -0.00 & & $0.37^{* * *}$ & $0.38^{* * *}$ \\
\hline RDWC Satisfaction & & 0.06 & 0.00 & & $0.19^{* * *}$ & $0.17^{* *}$ \\
\hline Waste room & & & $0.11^{*}$ & & & 0.06 \\
\hline Environment & & & -0.11 & & & $0.35^{* *}$ \\
\hline Supervision & & & 0.12 & & & $-0.24^{*}$ \\
\hline$R^{2}$ & 0.02 & 0.02 & 0.07 & 0.01 & 0.08 & 0.12 \\
\hline F & 1.70 & 1.77 & $2.64^{* * *}$ & 0.87 & $3.48^{* * *}$ & $2.9^{* * *}$ \\
\hline
\end{tabular}

...where $\mathrm{i}$ represents the individual; $\varepsilon_{\mathrm{i}}$ is the random error; $b_{1} \ldots b_{9}$ are parameters.

In Table 4, Model 3 of awareness revealed that the direct effect of the respondents' age was significantly and positively related to awareness of RDWC $\left(b_{2}=0.14\right.$, $p<0.01$ ), indicating that the elder is more likely to have the awareness of environmental issues. Furthermore, the cleanliness of the waste room was significantly and positively related to awareness of RDWC $\left(b_{7}=0.11\right.$, $p<0.1$, showing that if villages' waste rooms were clean and classified, it could raise public awareness of RDWC. Model 2 of behavior revealed that the direct effect of the attitude to waste management was significantly and positively related to RDWC behaviors $\left(b_{5}=0.37, p<0.01\right)$, indicating that when rural residents supported the implementation of RDWC, they were more likely to classify waste accurately. Furthermore, RDWC Satisfaction was significantly and positively related to RDWC behaviors $\left(b_{6}=0.19, p<0.01\right)$, showing that if rural residents were satisfied with RDWC in their village, they would do the RDWC actively. After the subject factors entered, the results for Model 3 showed a significant and positive interaction between the environment in respondents' village and waste

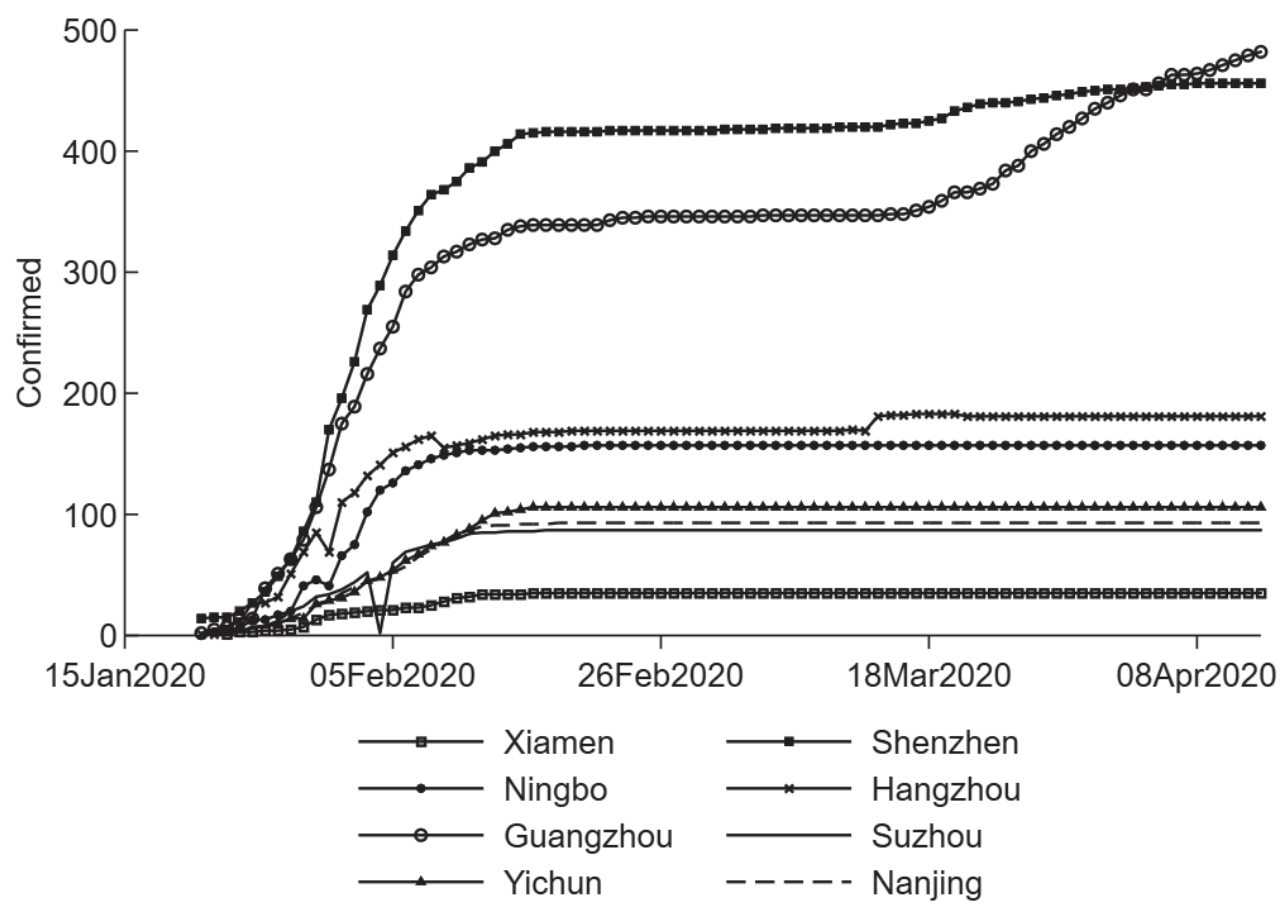

Fig. 1. The confirmed number of COVID-19 in Chinese eight cities. 
classification behavior $\left(b_{8}=0.35, p<0.01\right)$, demonstrating that when the environment was cleaner, the village residents were more possible to protect the environment by their behaviors. However, human supervision was significantly and negatively related to waste classification behavior $\left(b_{9}=-0.24, \mathrm{p}<0.1\right)$, showing that human supervision when collecting RDWC couldn't contribute to accurate waste classification behavior. And the impacts of Attitude and RDWC Satisfaction were similar to Model 2. Among the variables, subject perception is more important to awareness than the object factors, such as age, education. But for behavior, object factors seem more important. The public's RDWC behaviors are not consistent with awareness. The age and more education may change people's awareness but do little in the behavior. The change of behavior more relies on the external environment change than the internal changes.

\section{COVID-19 and the Performance of Domestic Waste Classification}

Domestic waste classification can cultivate the residents' habit of civilized behavior, low-carbon life concept, and ecological environment awareness in daily life. Besides, the domestic waste classification itself is a very active measure, which can effectively prevent the spread of the virus. Many cities in China have promoted domestic waste classification, including RDWC. Their organizational structures, mobilization systems, equipment, and facilities have played a significant role in winning the battle against novel coronavirus (COVID-19). So, we suspected the spread of COVID-19 could be associated with domestic waste classification in China. Thus, we explored the association between the number of COVID-19 cases and domestic waste classification performance. The daily confirmed numbers of COVID-19 cases were obtained

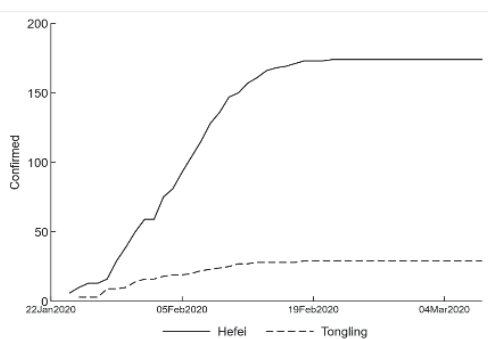

a) The confirmed number of COVID-19 in Hefei City and Tongling City, Anhui Province (Tongling City ranked $27^{\text {th }}$, Hefei City ranked $37^{\text {th }}$ )

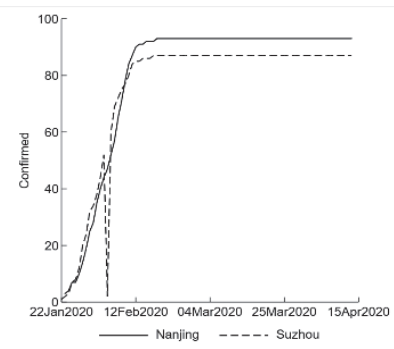

d) The confirmed number of COVID-19 in Nanjing City and Suzhou City, Jiangsu Province (Suzhou City ranked $7^{\text {th }}$, Nanjing City ranked $10^{\text {th }}$ )

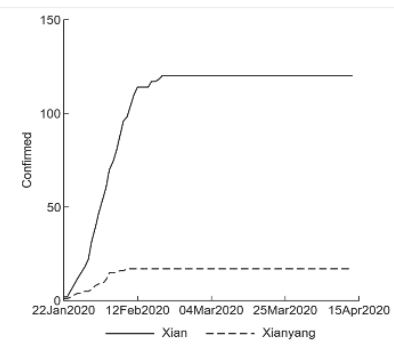

g) The confirmed number of COVID-19 in Xi'an City and Xianyang City, Shaanxi Province (Xianyang City ranked $21^{\text {st }}$, Xi' an City ranked $36^{\text {th }}$ )

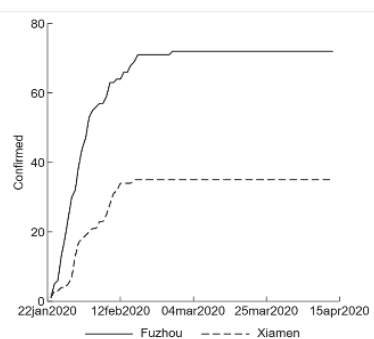

b) The confirmed number of COVID-19 in Fuzhou City and Xiamen City, Fujian Province (Xiamen City ranked $1^{\text {st }}$, Fuzhou City ranked $23^{\text {th }}$ )

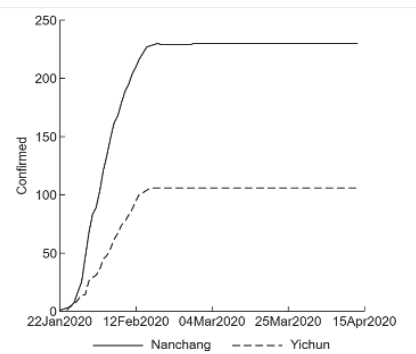

e) The confirmed number of COVID-19 in Nanchang City and Yichun City, Jiangxi Province (Yichun City ranked $8^{\text {th }}$, Nanchang City ranked $44^{\text {th }}$ )

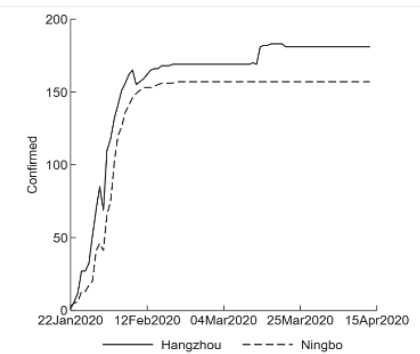

h) The confirmed number of COVID-19 in Hangzhou City and Ningbo City, Zhejiang Province (Ningbo City ranked $3^{\text {rd }}$, Hangzhou City ranked $4^{\text {th }}$ )

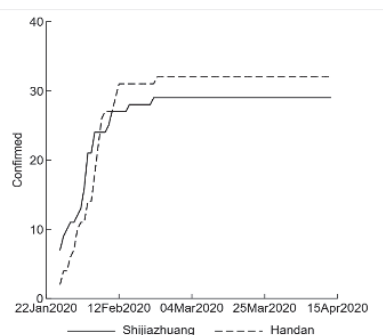

c) The confirmed number of COVID-19 in Shijiazhuang City and Handan City, Hebei Province (Shijiazhuang City ranked $33^{\text {th }}$, Handan City ranked $35^{\text {th }}$ )

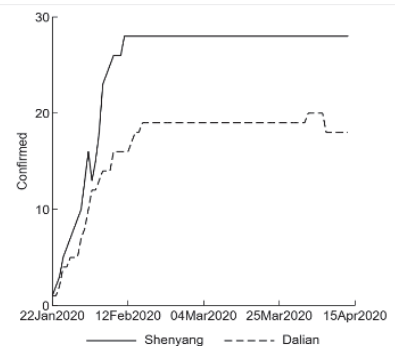

f) The confirmed number of COVID-19 in Shenyang City and Dalian City, Liaoning Province (Dalian City ranked $11^{\text {th }}$, Shenyang City ranked $26^{\text {th }}$ )

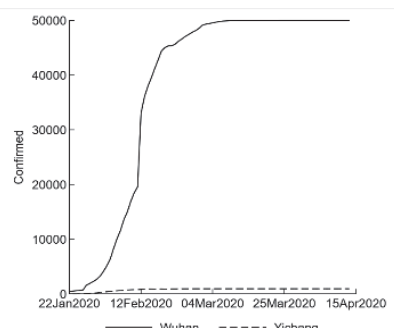

i) The confirmed number of COVID-19 in Wuhan City and Yichang City, Hubei Province (Yichang City ranked $13^{\text {th }}$, Wuhan City ranked $19^{\text {th }}$

Fig. 2. The confirmed number of COVID-19 in nine provinces with the epidemic situation related to domestic waste classification. 


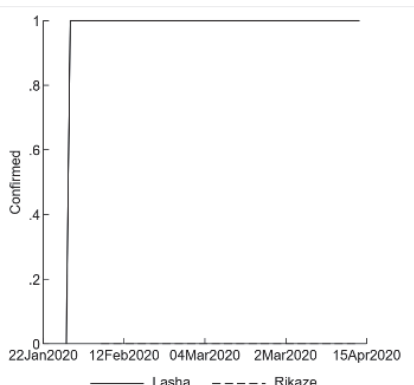

a) The confirmed number of COVID-19 in Lasha City and Rikaze City, Tibet Province (Lasha City ranked higher)

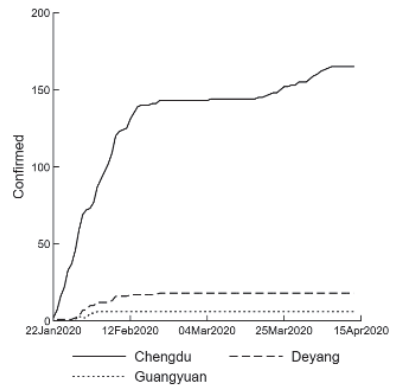

c) The confirmed number of COVID-19 in Chengdu City, Deyang City and Guangyuan City, Sicuan Province (Chengdu City ranked higher)

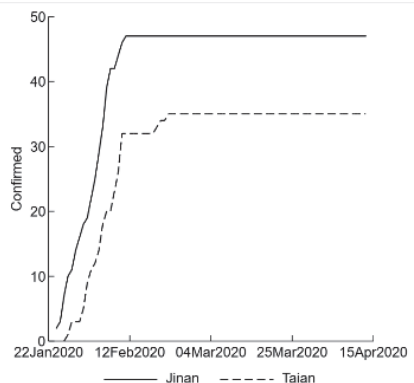

b) The confirmed number of COVID-19 in Jinan City and Taian City, Shandong Province (Jinan City ranked higher)
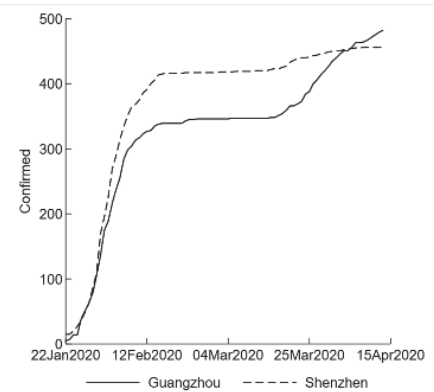

d) The confirmed number of COVID-19 in Guangzhou City and Shenzhen City, Guangdong Province (Shenzhen City ranked higher)

Fig. 3. The confirmed number of COVID-19 in four provinces with epidemic situation unrelated to domestic waste classification.

from the database of Sina Company from January 2020 to April 2020 (https://www.sina.com.cn.)

First, we compared the number of COVID-19 cases with domestic waste classification performance of different cities in the different provinces. Fig. 1 showed the confirmed number of COVID-19 in eight cities in China between January and April. These eight cities had the best performance of domestic waste classification in 2018. Municipalities directly under the Central Government are excluded here. It indicated that the cities with better domestic waste classification performance often have fewer confirmed numbers during this period.

Second, we compared the number of COVID-19 cases with domestic waste classification performance of different cities in the same province. Based on the waste classification performance rank given by UrbanRural Development of the People's Republic of China in 2018, a total of 13 provinces have more than one city on the list, namely Anhui, Fujian, Guangdong, Hebei, Hubei, Jiangsu, Jiangxi, Liaoning, Shandong, Shaanxi, Sichuan, Tibet, and Zhejiang. So, we compared the COVID-19 cases in the 13 provinces from January 2020 to April 2020. Fig. 2 and Fig. 3 showed the confirmed number of COVID-19 of each of the 13 provinces. We found that out of 13 provinces, 9 cities with high domestic waste classification ranks had better control of the COVID-19 epidemic situation. The trend of the epidemic situation in the same province was similar. By comparing the ranking of cities and epidemic control, we found that the greater the gap between the rankings of two cities in the same province, the greater the gap between the number of COVID-19 cases when the epidemic was stable. So, we concluded that the higher the ranking of domestic waste classification, the better the control of the COVID-19 epidemic.

In conclusion, by comparing cities in the same province and cities in different provinces, we found that there is a relationship between better domestic waste classification and better control of the epidemic. Through our study, the public's RDWC behaviors are positively influenced by the attitude to waste classification. Therefore, during the epidemic, promoting domestic waste classification which is helpful to control the epidemic can help residents to improve their attitudes toward domestic waste classification, thus affecting residents' domestic waste classification behavior greatly.

\section{Conclusions}

RDWC plays a significant role in the circular economy and sustainable management. However, research on public awareness and behaviors is scarce, especially using probability sampling and regression analyses. This study extends the theory of awareness 
and behaviors, exploring the effects of attitude to waste classification, satisfaction with the situation of RDWC, cleanliness of waste rooms, environment, human supervision, and demographics on public awareness and behaviors of RDWC. In this way, we talk about the influencing factors of public awareness and behaviors, so that we can provide more targeted effective advice. The conclusions are as follows: First, the public's RDWC awareness is positively influenced by the cleanliness of waste rooms, age, and educational level. Second, the public's RDWC behaviors are negatively influenced by human supervision but positively influenced by the attitude to waste classification, satisfaction with the situation of RDWC and environment. Third, the public's RDWC behaviors are not consistent with their awareness. Forth, there is a relationship between the number of COVID-19 confirmed cases and the public behavior of domestic waste classification. Compared to cities in the same province, cities with better domestic waste classification performance better-controlled COVID-19.

This study adds subject perception, object conditions, and demographic variables into the framework of the theory of awareness and behaviors, making it more complete, and proposes some specific advice for promoting the implementation of waste classification policies. However, from the survey, we find some specific problems when implementing waste classification policies.

First, the perception of the importance of RDWC is weak. Rural areas have formulated RDWC policies adapted to local conditions and provided basic waste classification facilities, but the trash cans are still mixed trash cans. Besides, the implementation of RDWC is not thorough enough. RDWC has still not received much attention.

Second, the knowledge of RDWC is irregular. The public knowledge of hazardous waste, recyclable waste, kitchen waste, and other waste is rather low and irregular. From the results of our survey, the average classification accuracy score of hazardous waste is higher than the recyclable waste. And, only $40 \%$ of the respondents participated in activities such as education on knowledge about waste classification. Insufficient publicity on the classification of RDWC may be an account of the case.

Third, the development of rural and urban areas in developing countries is unbalanced. As the world's largest developing country, China is facing a series of imbalances, especially the imbalance between urban and rural economic development. So, RDWC in China has not been given sufficient attention. Furthermore, poor infrastructure construction and lagged policies caused the classification and management of RDWC to be much more lagged than the urban areas.

From the study, we concluded that public behaviors toward RDWC can be influenced by increasing publicity efforts, improving the local environment, and taking more effective incentive measures. Also, a strong relationship between the number of COVID-19 cases and the waste classification performance revealed that the significance of the flexibility of waste classification policy. However, the implementation of a waste classification policy should not be rushed. It's easy to help rural residents to classify kitchen waste and other waste, but it's not that easy to help them distinguish the difference between hazardous waste, recyclable waste, kitchen waste, and other waste. So, the government should implement the appropriate RDWC methods and supporting infrastructure facilities fitted to the different rural areas step by step, publicize RDWC methods to improve public awareness, and provide an atmosphere beneficial to good collection habits and ecological environment perception.

RDWC is an essential part of waste management in a country, while, in rural areas of many countries, RDWC has not been paid much attention. Therefore, the patterns and experience of RDWC in Hangzhou are widely applicable. Promoting RDWC in developing countries can be achieved by appropriate incentive policies and supporting infrastructure in the short term. However, to cultivate durable public awareness and behaviors in RDWC, it is significant to change residents' subject perception of RDWC through proper publicity and education. For future research, the comparative analysis of the differences between rural and urban areas could be considered. And the quantitative analysis of the relationship between RDWC and COVID-19 may be discussed further.

\section{Acknowledgments}

This study is supported by the Zhejiang Social Science Founda-tion (21NDJC006Z),National Natural Science Foundation of China (Reference NO.71901195, NO.71803177), Zhejiang Provincial Natural Science Foundation of China (Reference NO.LQ20G030029, NO.LQ18G030004), Youth Innovation Project of Fundamental Research Funds of Zhejiang Sci-Tech University (NO.2019Q092, NO.2019Q091).

\section{Conflict of Interest}

The authors declare no conflict of interest.

\section{References}

1. LIU Y., HUANG J. Rural domestic waste disposal: an empirical analysis in five provinces of China. China Agricultural Economic Review, 6 (4), 558, 2014.

2. FEI F., QU L., WEN Z., XUE Y., ZHANG H. How to integrate the informal recycling system into municipal solid waste management in developing countries: Based on a China's case in Suzhou urban area. Resources, Conservation and Recycling, 110, 74, 2016. 
3. HU X., ZHANG M., YU J., ZHANG G. Food waste management in China: status, problems and solutions. Acta Ecologica Sinica, 32 (14), 4575, 2012.

4. LIAO, C., ZHAO, D., ZHANG, S., CHEN, L. Determinants and the moderating effect of perceived policy effectiveness on residents' separation intention for rural household solid waste. International journal of environmental research and public health, 15 (4), 726, 2018.

5. TAI J., ZHANG W., CHE Y., FENG D. Municipal solid waste source-separated collection in China: A comparative analysis. Waste Management, 31 (8), 1674, 2011.

6. CHUNG S.S., POON C.S. A comparison of wastereduction practices and new environmental paradigm of rural and urban Chinese citizens. Journal of Environmental Management, 62 (1), 3, 2001.

7. DHOKHIKAH Y., TRIHADININGRUM Y., SUNARYO S. Community participation in household solid waste reduction in Surabaya, Indonesia. Resources, Conservation and Recycling, 102, 153, 2015.

8. MUKHERJI S.B., SEKIYAMA M., MINO T., CHATURVEDI B. Resident knowledge and willingness to engage in waste management in Delhi, India. Sustainability, 8, 1065, 2016.

9. PAKPOUR A.H., ZEIDI I.M., EMAMJOMEH M.M., ASEFZADEH S., PEARSON H. Household waste behaviours among a community sample in Iran: An application of the theory of planned behaviour. Waste Management, 34 (6), 980, 2014.

10. KWETEY S., SAMUEL J.C., WILHEMINA A., ABUDU B.D. Household Demand and Willingness to Pay for Solid Waste Management Service in Tuobodom in the Techiman-North District, Ghana. American Journal of Environmental Protection, 2 (4), 74, 2014.

11. MA J., HIPEL K.W., HANSON M.L. An evaluation of the social dimensions in public participation in rural domestic waste source-separated collection in Guilin, China. Environmental Monitoring and Assessment, 190 (1), 35, 2017.

12. HAN Z., ZENG D., LI Q., CHENG C., SHI G., MOU Z. Public willingness to pay and participate in domestic waste management in rural areas of China. Resources, Conservation and Recycling, 140, 166, 2019.

13. WORLD HEALTH ORGANIZATION. Coronavirus disease 2019 (COVID-19): situation report, 51, 2020.

14. LIU W., TAO Z.W., LEI W., MING-LI Y., KUI L., LING Z., SHUANG W., YAN D., JING L., LIU H.G., MING Y., YI H. Analysis of factors associated with disease outcomes in hospitalized patients with 2019 novel coronavirus disease. Chinese Medical Journal, 133 (9), 1032, 2020.
15. BRAKE S.J., BARNSLEY K., LU W., MCALINDEN K.D., EAPEN M.S., SOHAL S.S. Smoking Upregulates Angiotensin-Converting Enzyme-2 Receptor: A Potential Adhesion Site for Novel Coronavirus SARS-CoV-2 (Covid-19). Journal of Clinical Medicine, 9 (3), 841, 2020.

16. MARTELLETTI L., MARTELLETTI P. Air Pollution and the Novel Covid-19 Disease: a Putative Disease Risk Factor. SN Comprehensive Clinical Medicine, 2, 383, 2020.

17. OGEN Y. Assessing nitrogen dioxide (NO2) levels as a contributing factor to coronavirus (COVID-19) fatality. Science of the Total Environment, 726, 138605, 2020.

18. MOL M.P.G., CALDAS S. Can the human coronavirus epidemic also spread through solid waste? Waste Management \& Research, 38 (5), 485, 2020.

19. GIOVANNI D.F., SABINO D.G. Public opinion and awareness towards MSW and separate collection programmes: A sociological procedure for selecting areas and citizens with a low level of knowledge. Waste Management, 30 (6), 958, 2010.

20. LI X., BI F., HAN Z., QIN Y., WANG H., WU W. Garbage source classification performance, impact factor, and management strategy in rural areas of China: A case study in Hangzhou. Waste Management, 89, 313, 2019.

21. YU B., SHEN C. Environmental regulation and industrial capacity utilization: An empirical study of China. Journal of Cleaner Production, 246, 118986, 2020.

22. JOMEEN J, MARTIN C.R. A psychometric evaluation of form $\mathrm{C}$ of the Multi-dimensional Health Locus of Control (MHLC-C) Scale during early pregnancy. Psychology, Health \& Medicine, 10 (2), 202, 2005.

23. BABBIE E.R. The Practice of Social Research 6th edition. Wadsworth Publishing, 1992.

24. BEATON D.E., BOMBARDIER, C., GUILLEMIN, F., FERRAZ, M. B. Guidelines for the process of crosscultural adaptation of self-report measures. Spine, 25 (24), 3186, 2000.

25. MARTÍNEZ-PEÑA R.M., HOOGESTEIJN A.L., ROTHENBERG S.J., CERVERA-MONTEJANO M.D., PACHECO-ÁVILA J.G. Cleaning products, environmental awareness and risk perception in Mérida, Mexico. PloS one, 8 (8), e 74352, 2013.

26. SONG Q., WANG Z., LI J. Exploring residents' attitudes and willingness to pay for solid waste management in Macau. Environmental Science and Pollution Research, 23 (16), 16456, 2016.

27. WANG Z., DONG X., YIN J. Antecedents of urban residents' separate collection intentions for household solid waste and their willingness to pay: Evidence from China. Journal of Cleaner Production, 173, 256, 2016. 